\title{
Total Triglyceride Quantification in Caenorhabditis elegans
}

Anjali Sandhu and Varsha Singh*

Department of Molecular Reproduction, Development, and Genetics, Indian Institute of Science, Bangalore 560012, India

*For correspondence: varsha@iisc.ac.in

[Abstract] Several studies suggest an important role of lipid metabolism in regulating longevity of Caenorhabditis elegans. Therefore, assays to quantify lipids have enormous value in understanding aging and pathologies associated with it. Approximately $70 \%$ of lipid metabolism genes in the nematode have orthologs in humans. Amenability of $C$. elegans to genetic manipulations has allowed investigations into the role of specific genetic factors in lipid metabolism. Here, we describe a protocol to quantify total triglycerides in C. elegans, which can be extended to studies of the effects of altered environmental and genetic factors on stored fats. This protocol quantifies the picomoles of the triglycerides, in whole worm lysate. Due to the sensitivity of the assay, it could help in identifying subtle changes in the total stored fat which are not discernible with microscopy techniques.

Keywords: Caenorhabditis elegans, Triglycerides, Fluorometry, Fat, Metabolism

[Background] Excess calories are often stored in the form of triacylglycerol or glycogen (Cohen, 2018). Abnormal levels of triglycerides (TAGs) have been implicated in heart diseases, pancreatitis, and atherosclerosis in humans (Cameron et al., 1974; Lee et al., 2003; Walther and Farese, 2012; Onal et al., 2017). TAGs are packed into lipid droplets in the cytosol. Lipid droplets are present in eukaryotic cells and vary in size from $20 \mathrm{~nm}$ to $100 \mu \mathrm{m}$ (Stobart et al., 1986; Suzuki et al., 2011). Lipid droplets consist of a hydrophobic core surrounded by a phospholipid monolayer on the outer side. These organelles undergo active biogenesis, maturation, and turnover. At the time of need, such as during caloric restriction or starvation, TAGs are hydrolyzed to generate energy (Walther and Farese, 2012). Like other eukaryotes, C. elegans also stores excess energy in the form of TAGs packed into lipid droplets (Ashrafi, 2007; Mak, 2012). The droplets are present predominantly in the intestine and hypodermis and can be easily visualized by staining with Sudan black, Oil-Red-O, BODIPY (Ex/Em=493/503), or Nile Red (Kimura et al., 1997; Ashrafi et al., 2003; O'Rourke et al., 2009; Yen et al., 2010; Dixit et al., 2020). However, these techniques do not provide an estimate of the absolute amounts of triglycerides. Here, we describe a biochemical method for the quantification of absolute levels of triglycerides in C. elegans, with sensitivity in picomolar concentration. In this assay, lipases hydrolyze TAGs to release free fatty acids and glycerol. Glycerol is further oxidized to generate a product that reacts with a probe to generate fluorescence at Ex/Em of 535/587. Outline of the protocol is shown in Figure 1. Biochemical quantification is useful for the detection of the glycerol moiety of the TAG, but it does not provide information on the fatty acid composition of stored fats in terms of saturated and 
desaturated fatty acids. This method can be utilized to study changes in total triglyceride content due to genetic pertubations, change in diet or pharmacological perturbations.

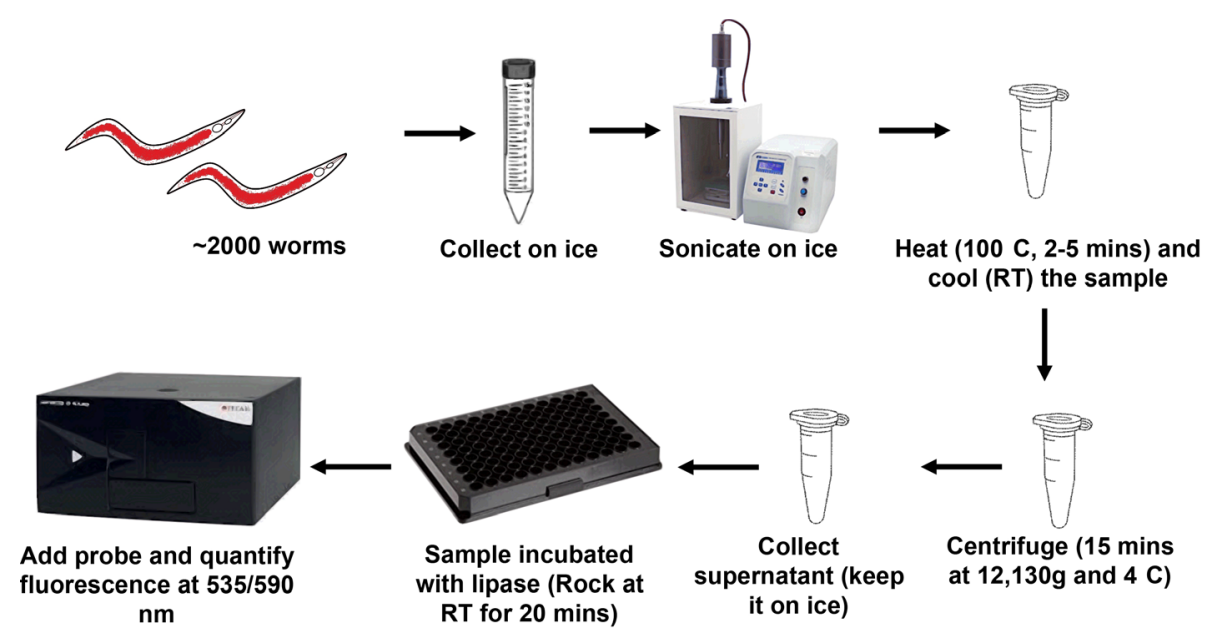

Figure 1. Triglyceride quantification procedure overview

\section{Materials and Reagents}

1. $1 \mathrm{~L}$ and $2 \mathrm{~L}$ Conical flasks (ThermoFisher Scientific, FisherBrand)

2. $60 \mathrm{~mm}$ Petri dish with triple vent (Tarsons, catalog number: 460061)

3. 96-well flat bottom black fluorescent reading plates (SPL Life sciences, catalog number: 30496)

4. $50 \mathrm{ml}$ graduated centrifuge tube (Tarsons, catalog number: 546021 )

5. $15 \mathrm{ml}$ graduated centrifuge tube (Tarsons, catalog number: 566041)

6. $0.45 \mu \mathrm{m}$ filters (GE Healthcare, Whatman ${ }^{\mathrm{TM}}$, catalog number: 9913-2504)

7. 0.010-inch diameter Platinum wire

8. Aluminum foil (PRS associates, MYFOIL)

9. $1.5 \mathrm{ml}$ microfuge tube (Trasons)

10. Caenorhabditis elegans

11. Escherichia coli OP50 (Glycerol stock)

12. $\mathrm{NaCl}$ (ThermoFisher Scientific, Qualigens, catalog number: 7647)

13. $\mathrm{MgSO}_{4}$ (ThermoFisher Scientific, SQ, catalog number: 10034)

14. $\mathrm{CaCl}_{2}$ (Merk Life Science, EMPLURA, catalog number: QE5Q651429)

15. $\mathrm{K}_{2} \mathrm{HPO}_{4}$ (Avantor ${ }^{\mathrm{TM}}$, RANKEM, catalog number: P2607)

16. $\mathrm{KH}_{2} \mathrm{PO}_{4}$ (ThermoFisher Scientific, Qualigens, catalog number: 7778)

17. $\mathrm{Na}_{2} \mathrm{HPO}_{4}$ (ThermoFisher Scientific, Qualigens, catalog number: 7558 )

18. $\mathrm{NaOH}$ (SDFCL, catalog number: $20252 \mathrm{K05}$ )

19. Sodium hypochlorite solution ( $\mathrm{NaOCl}$ ) (Sigma-Aldrich, catalog number: 239305)

20. Absolute ethanol (Merck Life Science, EMSURE, catalog number: 64-17-5)

21. Molecular grade water (SIGMA, catalog number: W4502)

22. Agar powder (HiMedia, catalog number: RM301) 
23. LB broth (BD Biosciences, Difco ${ }^{\mathrm{TM}}$ LB Broth Miller (Luria-Bertani), catalog number: 244620)

24. LB agar (BD Biosciences, Bacto ${ }^{\mathrm{TM}}$ Agar, catalog number: 214010)

25. Peptone (BD Biosciences, Bacto ${ }^{\mathrm{TM}}$ Peptone, catalog number: 211677)

26. Cholesterol (SIGMA, catalog number: C8667)

27. Streptomycin (Alfa Aesar, catalog number: J61299)

28. NP-40 solution (SIGMA, catalog number: 74385 )

29. BioVision triglyceride quantification colorimetric/fluorometric kit (BioVision, catalog number: K622)

Reagents provided in the BioVision kit

Triglyceride Assay Buffer (TAB)

Triglyceride Probe

Lipase

Triglyceride Enzyme Mix

Triglyceride Standard (1 $\mathrm{mM})$

30. Nematode growth media (see Recipes)

31. $1 \mathrm{M} \mathrm{KPO}_{4}$ (see Recipes)

32. $1 \mathrm{M} \mathrm{CaCl}_{2}$ (see Recipes)

33. $1 \mathrm{M} \mathrm{MgSO}_{4}$ (see Recipes)

34. $5 \mathrm{mg} / \mathrm{ml}$ Cholesterol (see Recipes)

35. $50 \mathrm{mg} / \mathrm{ml}$ Streptomycin (see Recipes)

36. $5 \mathrm{~N} \mathrm{NaOH}$ (see Recipes)

37. LB media (see Recipes)

\section{Equipment}

1. Water bath

2. Autoclave (JSR, model: JSAX-80)

3. Laminar flow (JSR, model: JSCB-1200SB)

4. BOD incubator (JSR, model: JSBI-840C)

5. Rocker (SHALOM, GEL ROCKER, model: SLM-GR-100)

6. Centrifuge (Hettich, Universal $320 \mathrm{R}, 1406$ )

7. Centrifuge (Eppendorf, Centrifuge $5424 \mathrm{R}$ )

8. Sonicator (BRANSON, DIGITAL SONIFIER 450)

9. Spectrophotometer (TECAN, model: Infinite M200 pro)

\section{Software}

1. $\mathrm{i}$-control ${ }^{\mathrm{TM}}$ (TECAN, https://lifesciences.tecan.com/plate readers/infinite 200 pro? $\mathrm{p}=\mathrm{Software}$ )

2. GraphPad Prism5 (PRISM, https://www.graphpad.com/scientific-software/prism/) 


\section{Procedure}

A. C. elegans maintenance

1. Streak E. coli OP50 on LB agar plates without any antibiotic (see Recipes) and incubate the plate for $12 \mathrm{~h}$ at $37^{\circ} \mathrm{C}$.

2. Inoculate a single OP50 colony into $10 \mathrm{ml}$ of LB media in a $50 \mathrm{ml}$ graduated centrifuge tube and let it grow overnight $(10-12 \mathrm{~h})$ at $37^{\circ} \mathrm{C}$.

3. Spot $\sim 150 \mu \mathrm{l}$ of overnight grown OP50 culture to $60 \mathrm{~mm}$ NGM plates and dry in laminar flow for $\sim 30 \mathrm{~min}$. These plates can be stored at room temperature (RT).

4. Using a heat sterilized platinum wire pick, transfer 5-6 gravid worms (Figure $2 A$ ) to an OP50 seeded NGM plate and propagate them at $20^{\circ} \mathrm{C}$ till they reach the adult stage and start laying eggs.

5. Adults worms can again be transferred on to a new NGM OP50 plate for maintenance.
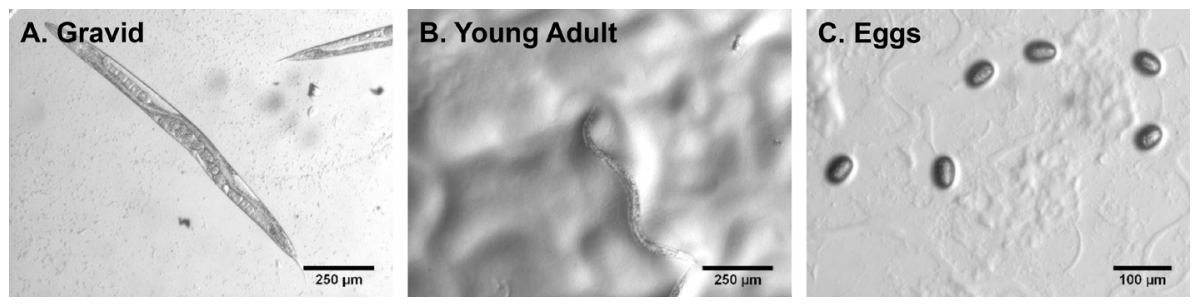

Figure 2. Image of a (A) gravid adult, (B) young adult, and (C) eggs of C. elegans

B. Lipid quantification

1. Preparation of synchronized population by taking $\sim 10$ gravid adults $\left(60-65 \mathrm{~h}\right.$ old worms at $20^{\circ} \mathrm{C}$, see Figure $2 \mathrm{~A}$ ) and allowing them to lay eggs for 6-8 $\mathrm{h}$ on NGM plates seeded with OP50. This yields about 500 eggs per plate. Incubate these plates at $20^{\circ} \mathrm{C}$ till worms reach the gravid adult stage.

2. Collect the gravid worms from 3 dishes into $6 \mathrm{ml} \mathrm{M9}$ buffer in a $15 \mathrm{ml}$ graduated centrifuge tube.

3. Let the worms settle down for $10 \mathrm{~min}$.

4. Remove excess M9 buffer without disturbing the pellet of worms and add $10 \mathrm{ml}$ autoclaved water.

5. Let the worms settle down and then remove water up to $2 \mathrm{ml}$ mark in the $15 \mathrm{ml}$ graduated centrifuge tube.

6. Prepare a $2 x$ bleach mix by adding $5 \mathrm{~N} \mathrm{NaOH}$ and $\mathrm{NaOCl}$ (bleach) in water (see Recipes).

7. Add $2 \mathrm{ml}$ of $2 x$ bleach mix to the suspension of worms in the water.

8. Vortex vigorously for $30 \mathrm{~s}$ to break open the worms. Check under a microscope to ascertain the release of eggs in the solution (Figure 2).

Note: The duration of vortexing can vary with the strength of the bleach. Vortex vigorously till worms break open and eggs are released in the solution.

9. Add $15 \mathrm{ml} \mathrm{M9}$ buffer immediately after eggs are released. 
10. Centrifuge at $850 \times g$ for 3 min for eggs to settle down at the bottom. Remove excess M9 buffer without disturbing the pellet.

11. Repeat Steps B9 and B10 twice.

12. Resuspend the eggs in $1 \mathrm{ml}$ of $\mathrm{M} 9$ buffer in the graduated centrifuge tube. Incubate on a tube rotator at $20^{\circ} \mathrm{C}$ for $18-20 \mathrm{~h}$.

13. Examine the egg suspension for hatching after 18-20 h.

14. Shake the tubes properly and spot three $5 \mu \mathrm{l}$ drops on a plain NGM plate. Count the number of worms in each spot. Take the average of three reads to estimate total numbers of worms present.

15. Spot hatched L1 larvae on five NGM OP50 plates with an average of 300-400 worms on each and propagate the worms at $20^{\circ} \mathrm{C}$ till the young adult stage $(45-48 \mathrm{~h}$ after spotting $\mathrm{L} 1$, see Figure 2).

16. Collect the worms in a $15 \mathrm{ml}$ graduated centrifuge tube using M9 buffer, wash twice with $10 \mathrm{ml}$ M9 buffer (samples to be on ice till Step B23).

17. Let the worms settle and remove excess M9 buffer.

18. Resuspend worms in $15 \mathrm{ml}$ of $5 \% \mathrm{NP}-40$ solution in water and let worms settle again.

19. Remove excess NP-40 solution and resuspend worms in $2 \mathrm{ml}$ of $5 \%$ NP-40 solution.

20. Spot $50 \mu \mathrm{l}$ of the suspension of worms and count the number of worms. Dilute, if necessary, to keep the same average number ( 40-50 worms per $50 \mu \mathrm{l})$ of worms across different samples.

21. Let the worms settle again on ice and resuspend in $500 \mu \mathrm{l}$ of $5 \% \mathrm{NP}-40$ solution.

22. Sonicate the worms in $5 \%$ NP-40 solution on ice for 30 min with $15 \mathrm{~s} \mathrm{ON}$ and $10 \mathrm{~s}$ OFF at $60 \%$ amplitude. Change the ice, if required, every $10 \mathrm{~min}$.

23. Transfer the sonicated lysate to a fresh $1.5 \mathrm{ml}$ microfuge tube.

24. Heat the sample to $100{ }^{\circ} \mathrm{C}$ in a water bath for 2-5 min and then let it cool at RT temperature. This is important to completely solubilize all the triglycerides in the samples.

25. Repeat Step B24 once.

26. Centrifuge at $4{ }^{\circ} \mathrm{C}$ for $2 \mathrm{~min}$ at $12,130 \times \mathrm{g}$.

27. Transfer the supernatant to a fresh $1.5 \mathrm{ml}$ microfuge tube without disturbing the pellet. Keep the supernatant on ice and discard the pellet.

28. Make 1:100 dilution of the sample in water for measurement.

C. Generation of a standard curve for triglycerides

1. Heat the triglyceride standard, provided in the BioVision kit, to $100^{\circ} \mathrm{C}$ in a water bath for $1 \mathrm{~min}$ and vortex for $1 \mathrm{~min}$.

2. Repeat Step C1 twice and let it cool. Make sure the solution is clear.

3. Dilute the $1 \mathrm{mM}$ triglyceride standard to $0.4 \mu \mathrm{M}(0.4 \mathrm{pmol} / \mu \mathrm{l})$ with triglyceride assay buffer (TAB).

4. Prepare buffer control (TAB alone) along with 1:5, 2:5, and 4:1 dilutions of $0.4 \mu \mathrm{M}$ triglyceride standard with $T A B$ to generate $0,4,8$, and 16 picomoles triglyceride per well for fluorometric quantification of triglycerides in a 96-well microtiter plate. Adjust volume to $50 \mu \mathrm{l}$ with TAB.

Note: For creating "0, 4, 8 and $16 \mathrm{pmol}$ triglyceride", we added 0, 10, 20, and $40 \mu \mathrm{l}$ of $0.4 \mu \mathrm{M}$ 
standard to 50, 40, 30, and $10 \mu \mathrm{l}$ of TAB buffer respectively. For technical duplicates, a total reaction volume of $100 \mu /$ should be prepared for each standard in $1.5 \mathrm{ml}$ microcentrifuge tubes.

5. Add $2 \mu \mathrm{l}$ lipase to each $50 \mu \mathrm{l}$ of standard and mix well. For duplicates, add $4 \mu \mathrm{l}$ of lipase to each $100 \mu \mathrm{l}$ standard, mix well, and split $50 \mu \mathrm{l}$ in each well of the 96-well microtiter plate. Incubate the mix at room RT on a rocker for 20 min.

Note: Flat bottom black 96-well microtiter plate is used for this experiment.

6. Prepare the TAG reaction mix by mixing $2 \mu \mathrm{I}$ TAG enzyme mix, $0.4 \mu \mathrm{I}$ TAG probe, and $47.6 \mu \mathrm{l}$ of TAB for each well. Prepare a master mix for the total number of standard wells plus one buffer reaction to reduce variation. For example, for 4 standards (including buffer control) in duplicates, it will be $18 \mu \mathrm{l} \mathrm{TAG} \mathrm{enzyme} \mathrm{mix,} 3.6 \mu$ TAG probe, and $428.4 \mu$ of TAB buffer. A buffer reaction is added to take care of volume loss due to pipetting errors.

Note: Protect the reaction from light.

7. Add $50 \mu$ of the TAG reaction mix to buffer control and each standard well of the 96-well microtiter plate. Incubate the reaction on the rocker for $60 \mathrm{~min}$ at RT.

8. Measure the fluorescence at Ex/Em of 535/590 nm using TECAN Infinite M200 pro spectrophotometer (see Figure 3). 
Step 1: Raw data obtained at $590 \mathrm{~nm}$

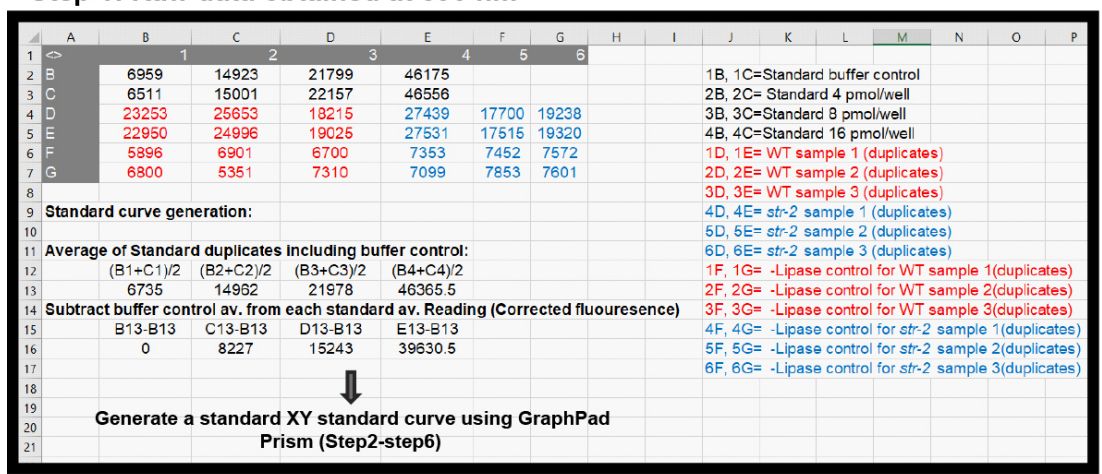

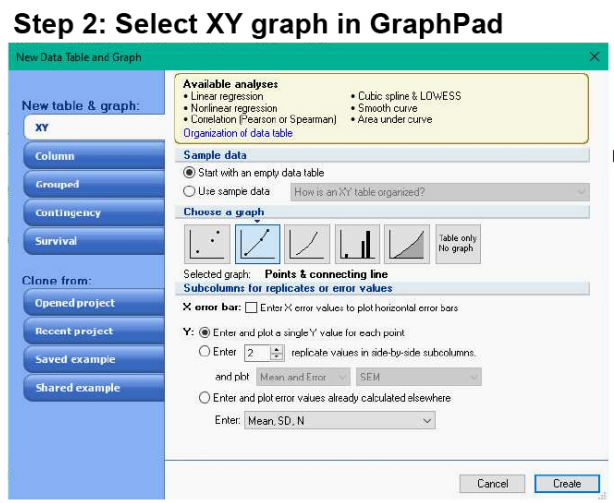

Step 6: Curve obtained after applying linear regression

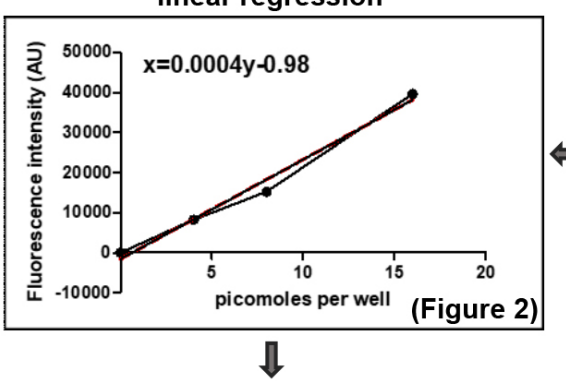

To be used in figure 6
Step 3: Enter values in the sheet

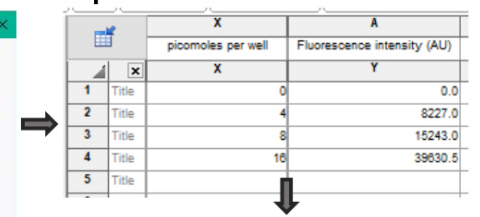

Step 4: Curve obtained

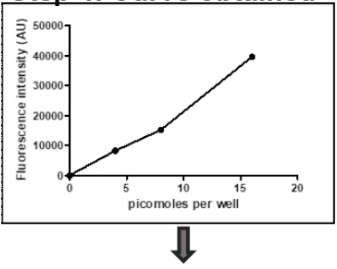

Step 5: Apply liner regression from 'Analyze Data'

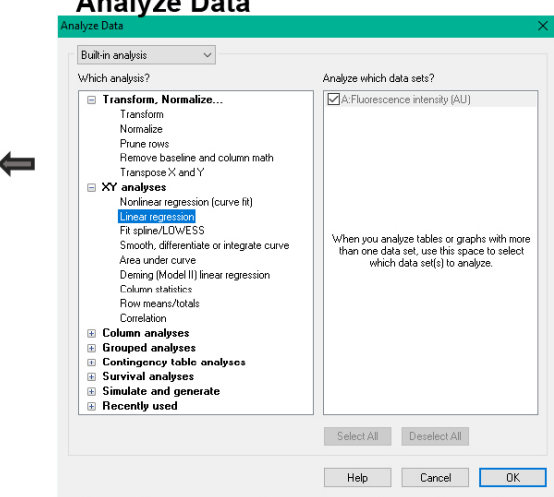

Figure 3. Steps for generation of triglyceride standard curve using Biovision kit for triglyceride quantification

9. Generate standard curve by plotting fluorescence vs triglycerides concentration (pmol) using PRISM (see steps in Figure 3). Obtain a fit by applying linear regression.

10. The standard curve is used to interpolate values of $x$ (triglyceride concentrations) for known values of y (follow steps in Figure 4). 


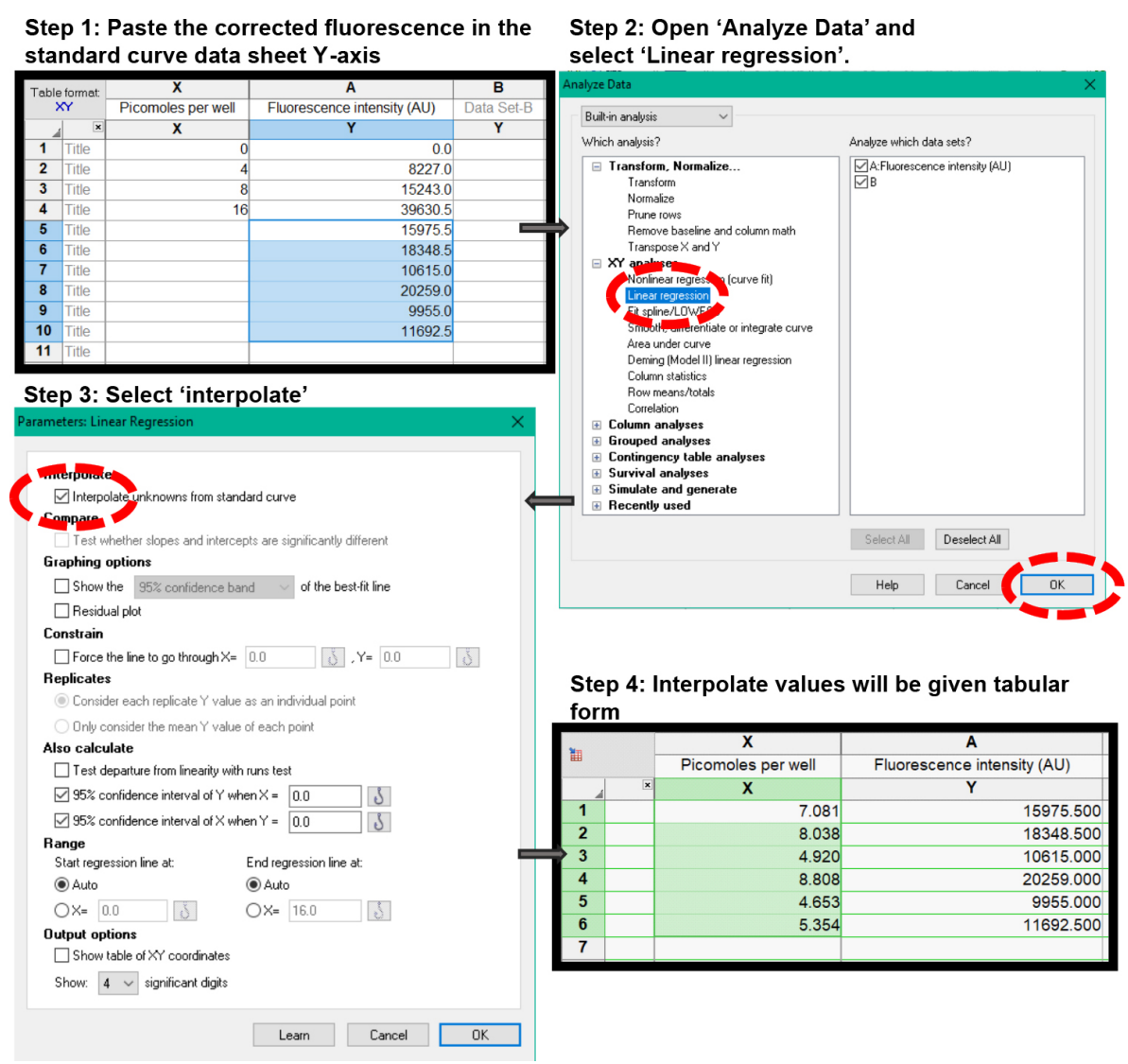

Figure 4. Interpolation from the standard curve to obtain triglyceride concentration in biological samples

D. Measurement of triglycerides in C. elegans samples

1. Dilute worm supernatant (from Step B28) to 1:2, 1:5, and 1:10 with TAB to make up the final volume to $50 \mu \mathrm{l}$ in a 96-well microtiter plate, in duplicates.

2. Add $2 \mu$ l lipase to each sample and mix it well. Incubate the mix at RT on a rocker for $20 \mathrm{~min}$.

3. Include no lipase control for each sample to measure basal level glycerol present in the sample.

4. For each well, prepare $50 \mu \mathrm{l}$ of triglyceride reaction mix by adding $2 \mu \mathrm{l}$ Triglyceride enzyme mix, $0.4 \mu \mathrm{l}$ triglyceride probe, and $47.6 \mu \mathrm{I}$ TAB. Prepare a single master mix for all the wells.

Note: Protect the reaction from light.

5. Add $50 \mu \mathrm{l}$ of the triglyceride reaction mix to each sample well of the 96-well microtiter plate (from Step D2) and incubate at RT for $60 \mathrm{~min}$.

6. Measure the fluorescence at $\mathrm{Ex} / \mathrm{Em}$ of $535 / 590 \mathrm{~nm}$ for each sample with lipase and respective no lipase control (raw values shown in the snapshot in Figure 5). 


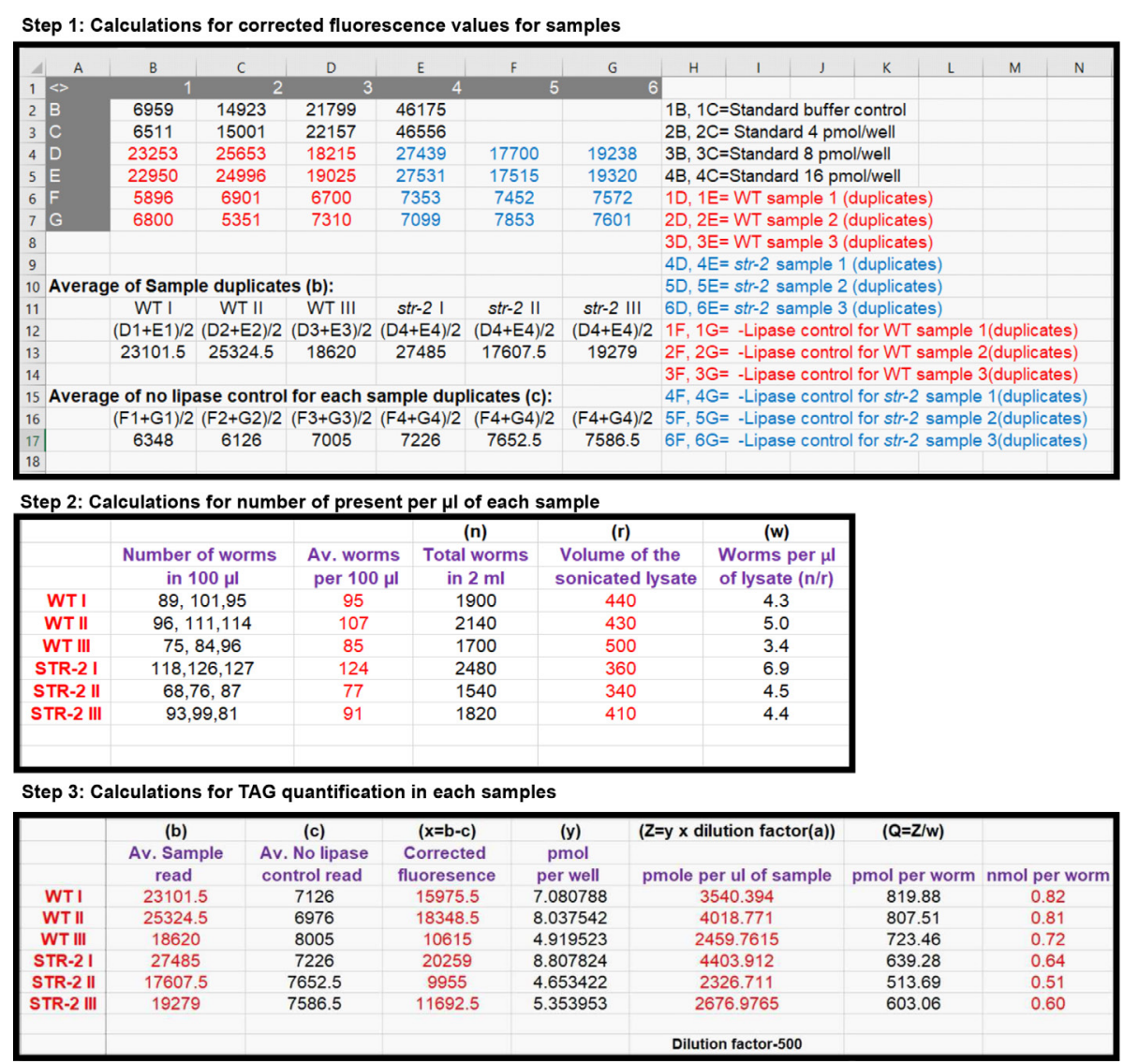

Figure 5. Calculations for triglyceride quantification in C. elegans samples

\section{Data analysis}

1. Subtract the fluorescence value of no lipase control from fluorescence value of respective worm sample with lipase. This provides corrected fluorescence value.

2. Apply the corrected fluorescence values to the triglyceride linear regression fit line (from Step C9) to get the picomoles of TAGs present in sample per well by interpolation in GraphPad Prism5 (see Figure 4 and Figure 5).

3. Calculate the concentration of triglycerides per $\mu \mathrm{l}$ in worm samples (Figure 5).

$$
Z=\frac{x}{a} * d
$$

where,

Z: picomoles of triglycerides per $\mu$ l of the sample

a: volume of sample added to the well

d: sample dilution factor

4. Absolute amount of triglycerides present per worm can be calculated (Figure 5)

$$
Q=\frac{(Z)}{w}
$$


where,

Q: picomoles of triglycerides per worm

w: number of worms per present ul of the sample

$$
w=\frac{(n)}{r}
$$

where,

$\mathrm{n}$ : total number of worms for each sample (from Step B20)

$r$ : volume of worm suspension in Step B19

Here, we have shown an example of TAGs quantification in wild type N2 animals (denoted as WT) and str-2 (ok3148) animals. STR-2 chemosensory G-protein coupled receptor controls the life span of $C$. elegans at high temperatures by regulating fat metabolism. str-2 mutants have reduced total lipid content as confirmed by Oil-Red-O staining and triglycerides quantification by BioVision kit (Figure 6). For WT and str-2 (ok3148) animals, we found that the triglyceride level was $0.78 \pm 0.03$ and $0.58 \pm 0.03$ nanomoles per worm respectively (Dixit et al., 2020). One of the caveat of the biochemical method is that it can not provide information on the spatial distribution of stored fats in various tissues of worms. Thus, a combination of staining methods and biochemistry is desirable for the study of fat metabolism in worms.

A

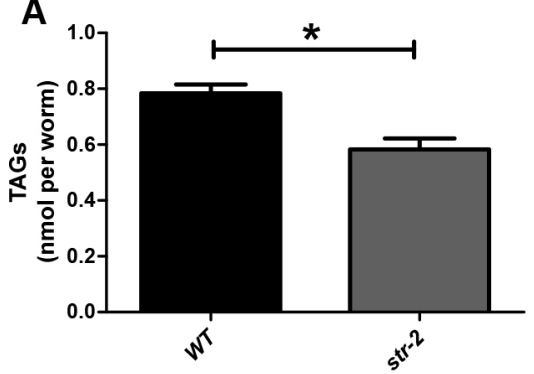

B

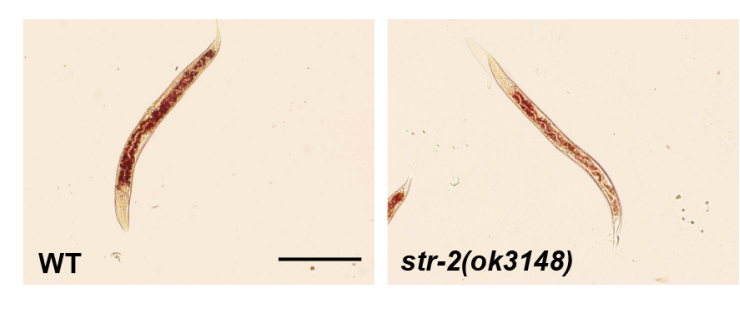

Figure 6. Triglycerides levels in WT and str-2 (ok3148) mutant of C. elegans. A. Mean \pm SEM triglycerides/worm in WT and str-2 animals. B. Lipids droplets stained by Oil-Red-O in WT and str-2 animals (Scale bar: $200 \mu \mathrm{m}$ ).

\section{$\underline{\text { Recipes }}$}

1. Nematode growth media $(1 \mathrm{~L})$

$3 \mathrm{~g} \mathrm{NaCl}$

$2.5 \mathrm{~g}$ Peptone

$17 \mathrm{~g}$ Agar

Water up to $1 \mathrm{~L}$

Autoclave the medium at $121^{\circ} \mathrm{C}$ and $15 \mathrm{psi}$ for $30 \mathrm{~min}$

Cool down the media to $\sim 50^{\circ} \mathrm{C}$ and add the following: 
$1 \mathrm{ml} 1 \mathrm{M} \mathrm{CaCl}_{2}$

$1 \mathrm{ml} 1 \mathrm{M} \mathrm{MgSO}_{4}$

$1 \mathrm{ml}$ of $5 \mathrm{mg} / \mathrm{ml}$ Cholesterol

$1 \mathrm{ml} 50 \mathrm{mg} / \mathrm{ml}$ streptomycin

$25 \mathrm{ml} 1 \mathrm{M} \mathrm{KPO}_{4}$

Mix well and pour in $60 \mathrm{~mm}$ Petri dish

2. $1 \mathrm{M} \mathrm{KPO}_{4}(200 \mathrm{ml})$

$21.66 \mathrm{~g}$ of $\mathrm{KH}_{2} \mathrm{PO}_{4}$

$7.12 \mathrm{~g}$ of $\mathrm{K}_{2} \mathrm{HPO}_{4}$

Water up to $200 \mathrm{ml}$

Autoclave the preparation at $121^{\circ} \mathrm{C}$ and $15 \mathrm{psi}$ for $30 \mathrm{~min}$

3. $1 \mathrm{M} \mathrm{CaCl}_{2}(100 \mathrm{ml})$

$14.7 \mathrm{~g}$ of $\mathrm{CaCl}_{2}$

Water up to $100 \mathrm{ml}$

Autoclave the solution at $121{ }^{\circ} \mathrm{C}$ and $15 \mathrm{psi}$ for $30 \mathrm{~min}$

4. $1 \mathrm{M} \mathrm{MgSO}_{4}(100 \mathrm{ml})$

$12.037 \mathrm{~g}$ of $\mathrm{MgSO}_{4}$

Water of $100 \mathrm{ml}$

Autoclave the solution at $121^{\circ} \mathrm{C}$ and $15 \mathrm{psi}$ for $30 \mathrm{~min}$

5. $5 \mathrm{mg} / \mathrm{ml}$ Cholesterol

$0.25 \mathrm{~g}$ of cholesterol

$50 \mathrm{ml}$ absolute ethanol

Filter sterilize the solution with $0.45 \mu \mathrm{m}$ filter

6. $50 \mathrm{mg} / \mathrm{ml}$ Streptomycin

$0.5 \mathrm{~g}$ of streptomycin

Water up to $10 \mathrm{ml}$

Filter sterilize with $0.45 \mu \mathrm{m}$ syringe filter

7. $5 \mathrm{~N} \mathrm{NaOH}$

$8 \mathrm{~g} \mathrm{NaOH}$

Water up to $40 \mathrm{ml}$

Filter sterilize with $0.45 \mu \mathrm{m}$ syringe filter

8. LB media

$2.5 \mathrm{~g} \mathrm{LB}$ broth

water up to $100 \mathrm{ml}$

Autoclave the LB broth at $121^{\circ} \mathrm{C}$ and $15 \mathrm{psi}$ for $30 \mathrm{~min}$

9. LB agar

$2.5 \mathrm{~g}$ LB broth

$2 \mathrm{~g}$ agar

Water up to $100 \mathrm{ml}$ 
Autoclave the preparation at $121^{\circ} \mathrm{C}$ and $15 \mathrm{psi}$ for $30 \mathrm{~min}$

Cool down the media to $\sim 50^{\circ} \mathrm{C}$ and pour in $60 \mathrm{~mm}$ Petri dishes

10. $\mathrm{M9}$ buffer (500 ml)
$1.5 \mathrm{~g} \mathrm{KH}_{2} \mathrm{PO}_{4}$
$3 \mathrm{~g} \mathrm{Na}_{2} \mathrm{HPO}_{4}$
$2.5 \mathrm{~g} \mathrm{NaCl}$
$0.5 \mathrm{ml}$ of $1 \mathrm{M} \mathrm{MgSO}_{4}$

Water up to $500 \mathrm{ml}$

Autoclave the solution at $121^{\circ} \mathrm{C}$ and $15 \mathrm{psi}$ for $30 \mathrm{~min}$

11. $2 x$ Bleach Mix $(2 \mathrm{ml})$

$400 \mu \mathrm{I} 5 \mathrm{~N} \mathrm{NaOH}$

$900 \mu \mathrm{l}$ of $\mathrm{NaOCl}$ (bleach)

Water up to $2 \mathrm{ml}$

\section{Acknowledgments}

This work was supported by the Wellcome Trust/DBT India Alliance Fellowship (Grant no. IA/I/13/1/500919) awarded to Varsha Singh.; 2) This protocol was used in our original study in Dixit et al. (2020).

\section{Competing interests}

We declare no financial or non-financial competing interests.

\section{References}

1. Ashrafi, K. (2007). Obesity and the regulation of fat metabolism. WormBook: 1-20.

2. Ashrafi, K., Chang, F. Y., Watts, J. L., Fraser, A. G., Kamath, R. S., Ahringer, J., and Ruvkun, G. (2003). Genome-wide RNAi analysis of Caenorhabditis elegans fat regulatory genes. Nature 421(6920): 268-272.

3. Cameron, J. L., Capuzzi, D. M., Zuidema, G. D., and Margolis, S. (1974). Acute pancreatitis with hyperlipemia. Evidence for a persistent defect in lipid metabolism. Am J Med 56(4): 482487.

4. Cohen, S. (2018). Lipid Droplets as Organelles. Int Rev Cell Mol Biol 337: 83-110.

5. Dixit, A., Sandhu, A., Modi, S., Shashikanth, M., Koushika, S., Watts JL., and Singh, V. (2020) Neuronal control of lipid metabolism by STR-2 G protein coupled receptor promotes longevity in Caenorhabditis elegans. AGING CELL 19: e13160. 
6. Kimura, K. D., Tissenbaum, H. A., Liu, Y. and Ruvkun, G. (1997). daf-2, an insulin receptor-like gene that regulates longevity and diapause in Caenorhabditis elegans. Science 277(5328): 942946.

7. Lee, C. H., Olson, P. and Evans, R. M. (2003). Minireview: lipid metabolism, metabolic diseases, and peroxisome proliferator-activated receptors. Endocrinology 144(6): 2201-2207.

8. Mak, H. Y. (2012). Thematic review series: Lipid droplet synthesis and metabolism: From yeast to man: Lipid droplets as fat storage organelles in Caenorhabditis elegans. J Lipid Res 53(1): 28.

9. Onal, G., Kutlu, O., Gozuacik, D. and Emre, S. D. (2017). Lipid droplets in health and disease. Lipids Health Dis 16(1): 1-15.

10. ORourke, E. J., Soukas, A. A., Carr, C. E. and Ruvkun, G. (2009). C. elegans major fats are stored in vesicles distinct from lysosome-related organelles. Cell Metab 10(5): 430-435.

11. Stobart, A. K., Stymne, S. and Höglund, S. (1986). Safflower microsomes catalyse oil accumulation in vitro: a model system. Planta 169(1): 33-37.

12. Suzuki, M., Shinohara, Y., Ohsaki, Y. and Fujimoto, T. (2011). Lipid droplets: size matters. $J$ Electron Microsc 60(suppl_1): S101-S116.

13. Walther, T. C. and Farese Jr, R. V. (2012). Lipid droplets and cellular lipid metabolism. Annu Rev Biochem 81: 687-714.

14. Yen, K., Le, T. T., Bansal, A., Narasimhan, S. D., Cheng, J. X. and Tissenbaum, H. A. (2010). $\underline{A}$ comparative study of fat storage quantitation in nematode Caenorhabditis elegans using label and label-free methods. PLOS ONE 5(9): e12810. 